\title{
MODELING THE SUGAR CANE LOGISTICS FROM FARM TO MILL
}

\author{
Marcelo Moretti Fioroni \\ Douglas José da Silva \\ Luiz Augusto G. Franzese \\ Paragon Decision Sciences \\ Rua Arminda, 93, $5^{\text {th }}$ floor \\ 04545-100 São Paulo, BRAZIL
}

\author{
Mário José Barbosa Cerqueira Júnior \\ Daniel de Amorim de Almeida \\ Raízen S/A \\ Bairro Costa Pinto, $\mathrm{s} / \mathrm{n}$ \\ 13411-900 Piracicaba-SP, BRAZIL
}

\begin{abstract}
A continuous and discrete system gets distinct approach from modelers, since both have very particular characteristics. Some simulation tools are specialized in one system or another, but the great majority focuses on discrete modeling. However, there are many hybrid systems where a continuous process interfaces with discrete. Despite being possible to model both systems with particular modeling tools, they have to be properly connected. An example of hybrid system is the ethanol production chain, where the transport of the raw material sugar cane has important interactions between the main components of the chain, where there is exchange of equipment, transport and interface of continuous systems with discrete, and vice versa. This study presents the algorithms and techniques used to model the logistics operations of the Alcohol/Sugar producer Raízen, developed using the SIMIO simulation tool.
\end{abstract}

\section{INTRODUCTION}

The world watched in recent years a growing concern with the issue of energy, mainly big oil dependency, which led to the research for alternative and sustainable fuels at the heart of current society. But in Brazil this quest began already in the 1980s, during the first global oil crisis, which led to the development of technologies of production, distribution and consumption of ethanol.

Brazilian society is already accustomed to the use of ethanol, and virtually all its vehicular fleet accepts this alternative fuel. There is a robust structure of production and distribution. Ethanol is produced from sugar cane, and this raw material is grown in large territorial extensions in the main Brazilian states. Transportation, therefore, is a critical step of the production chain, and suffers from the problems of traditional agricultural logistics: low productivity on off-season, impact of rain in the transportation time or even interruptions, sugar cane quality variation per planted area, and the need of changing harvest location.

The cane is transported to sugar and alcohol production plants, where it is selected, chopped, milled and processed. This transport is always done by the road modal, with various types of truck.

Ethanol production is strategic for the society and the country, that's why there is a great motivation to study and improve their performance through operational research techniques, in particular the simulation. In fact, studies on ethanol production using simulation are performed in Brazil since the late 1990s, having accompanied the evolution of the computational tools for this type of study.

The ethanol supply chain has specific components that, alone, are similar to other business models, mainly the agricultural transportation. However, uniting these components, this string becomes unique, with new interactions between its steps. To flow throughout the system, the cane passes through discrete 
and continuous modal types. And the discrete transportation by trucks has unique features, such as the exchange of dollies (carts) throughout the process. Figure 1 below shows a comprehensive diagram of the cane transportation process, where one can observe the major processes, system characteristics and interference.

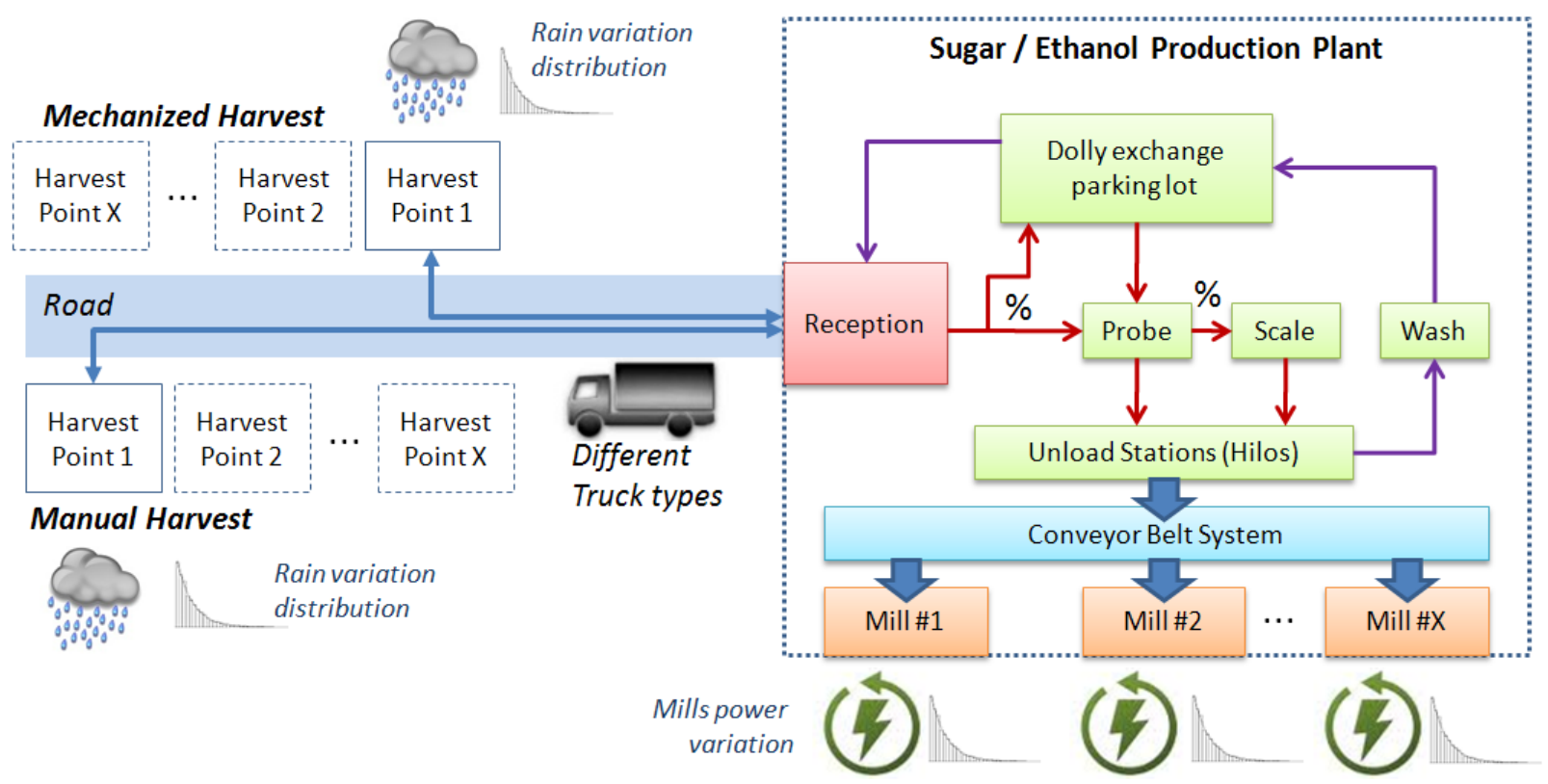

Figure 1: Sugar cane process.

An evaluation between continuous and discrete simulations made by Brito et al. (2011) have concluded that hybrid approaches, considering both systems working together, have great advantages over individual approaches studying both systems separated, which confirms the relevance of this study.

The problem of combining continuous and discrete systems in simulation models is not new. It is described by Roth (1988), which suggests a link between both systems using variable thresholds detectors. When a continuous variable reaches certain value, a discrete event or entity is triggered. The study of O'Reilly et al. (1985) uses continuous buffers between discrete processes in a manufacturing system. This approach is not an interface between discrete and continuous, but a continuous representation of a discrete system. In the work of Szymanski and Chen (2000), this link is performed by a synchronization agent between discrete and continuous models running in different servers. This case is very specific and adds complexity to the solution, including a third element (besides the discrete and continuous systems), that is the synchronization agent. Should be used only if other options are not feasible.

Stchedroff and Cheng (2003) describes an event based triggering method, used to model a continuous system of pipelines in a discrete-event simulation tool. This approach is adequate when the simulated system have only continuous processes, since there is no interface to any discrete process. A discrete representation of the continuous system was proposed by Kuo et al. (2001) and detailed by Fioroni et al. (2007), where small portions of the continuous flow are represented as discrete elements. That is the approach used in this study.

\section{CONCEPTUAL MODEL}

The objective of this study is to present the algorithms and procedures to model the various stages of the transport of sugar cane, since the cane farms until the entry into mills. The overall flow of the system is shown in Figure 2, and is a variation of the one presented by Rangel et al. (2010). 


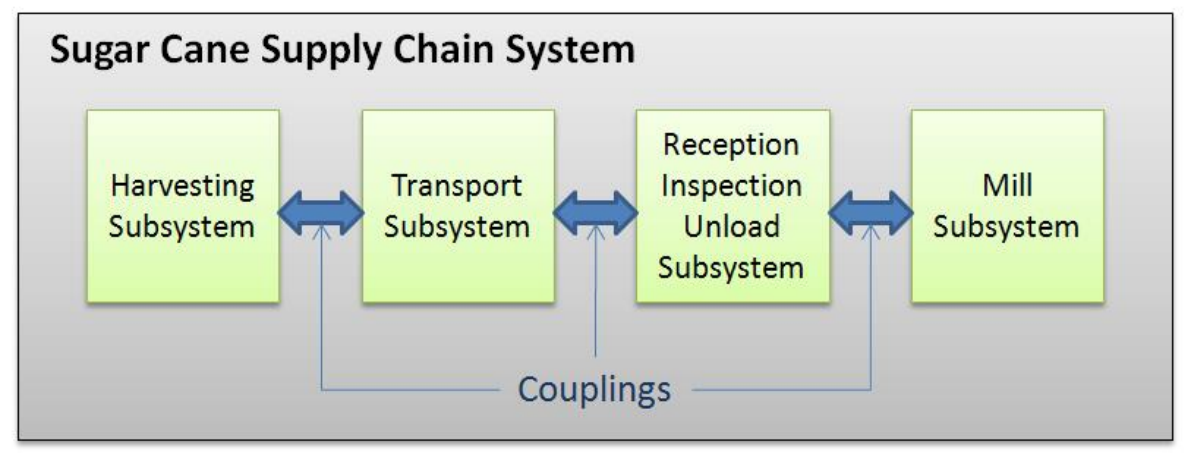

Figure 2: General system diagram.

In this figure, the following subsystems can be observed:

- Harvesting Subsystem: Where harvest occurs and all the operations needed to make a load of sugar cane for road transportation.

- Transport Subsystem: Transport of sugar cane produced by several types of trucks with different capacities and purposes. Its final destination is always a productive plant.

- Reception / Inspection / Unload Subsystem: This subsystem covers all activities relating to the reception of the material in the production plant, involving inspection, washing and exchanging dollies between the fleet of external and internal trucks, ending in the unload of the cane at the hopper.

- Mill Subsystem: Where the cane is milled, leaving it ready for production of ethanol or sugar.

The processes and algorithms between these subsystems are presented in the following sections.

\subsection{Processes from Harvesting to Transport}

The subsystem of Harvesting continuously generates chopped and whole cane, suffering variations relating to maintenance and other factors inherent of the production process.

The road fleet trucks need to wait for a lot to be complete, or an amount of cane ready to load, i.e., a discrete element. The process is different for a load of chopped of whole cane.

In the case of whole sugar cane, the process occurs as seen in Figure 3, where the cane arrives and is left in a stock broker and directly loaded in the arriving trucks. Intermediate stock is limited, if the trucks do not arrive with appropriate frequency, the harvesting process is hindered.

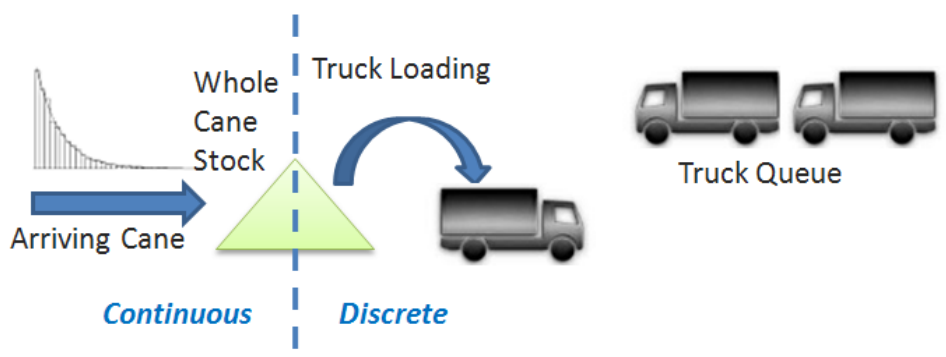

Figure 3: Whole cane loading. 
In the case of chopped/shattered cane, illustrated in Figure 4, there is a limited amount of carts/dollies that should be loaded. When a truck arrives with an empty dolly, it releases it, and attaches a loaded dolly. This system accelerates the process of transportation, because the load process stays apart from the cycle. However, if there is missing empty trailers, the harvesting process will also be harmed.
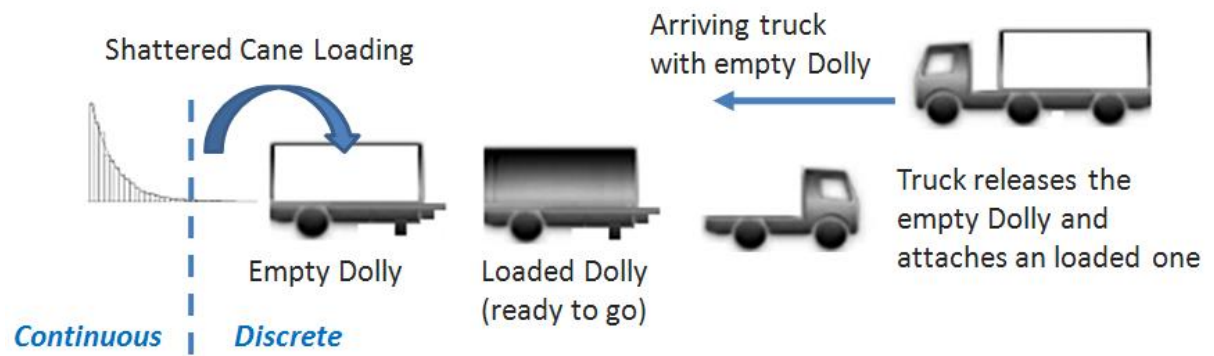

Figure 4: Shattered cane loading.

The interface between harvesting and transport is done in two ways, depending on the type of cane. Both are being shown in the flowchart in Figure 5, where you can see the conversion of a discrete to a continuous system.

The cane is continuously provided by harvest, but on the model, this process is represented by a time interval, which is equivalent to the total time to form a batch, or cart ready for transport. This time varies depending on the level of interference on the process.

Chopped Cane Process

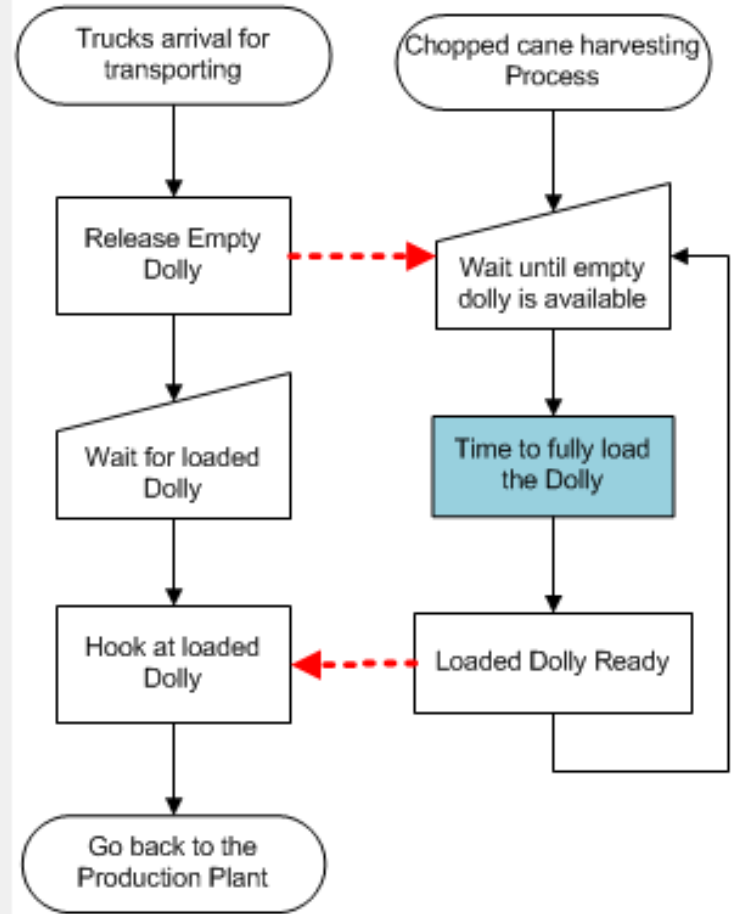

Whole Cane Process

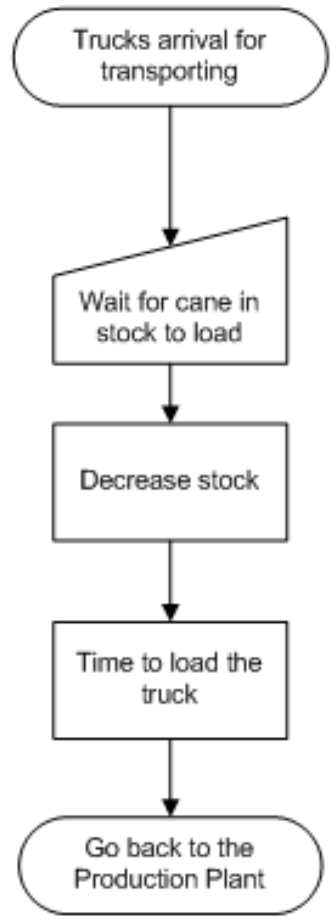

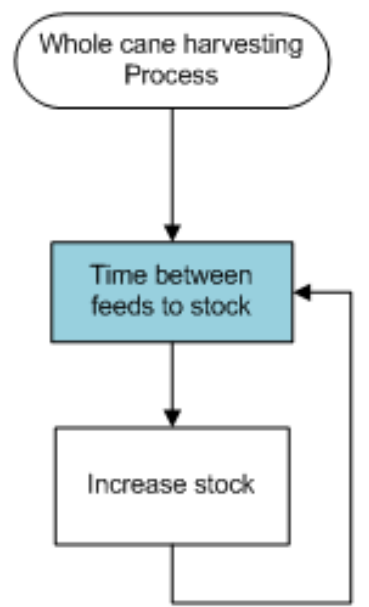

Dolly flow

Cane arriving from harvest - may suffer interferences 


\section{Fioroni, Silva, Franzese, Cerqueira Junior, and Almeida}

Figure 5: Harvest-transport interface algorithm.

\subsection{Processes from Transport to Reception}

The reception, that involves various bureaucratic procedures and quality control, also performs the dollies exchange between external and internal truck fleet. A parking lot is the connection point between the two fleets, serving to leave empty and loaded dollies waiting for their trucks, as shown in Figure 6.

This way, the trucks do not accompany the cane across the whole path from farm to unloading. Only the dollies make the complete process. This is not the case of whole cane trucks, which follows a much simpler processes, going directly to the unloading stations. This process has no coupling step to the reception, being done directly with the milling step.

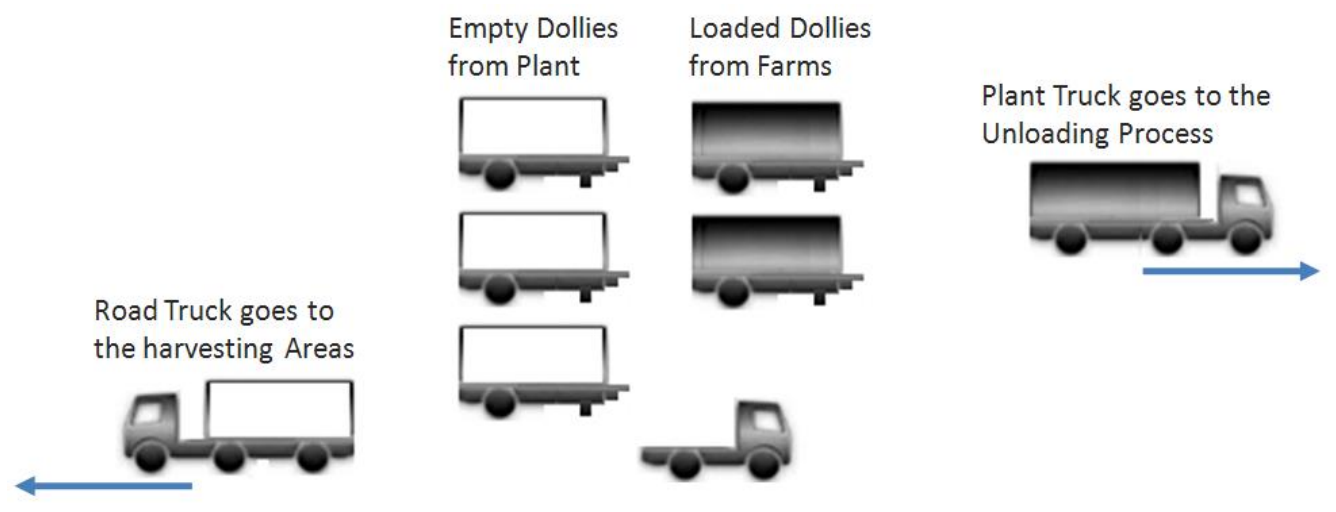

Figure 6: Shattered cane trucks exchanging dollies at the plant.

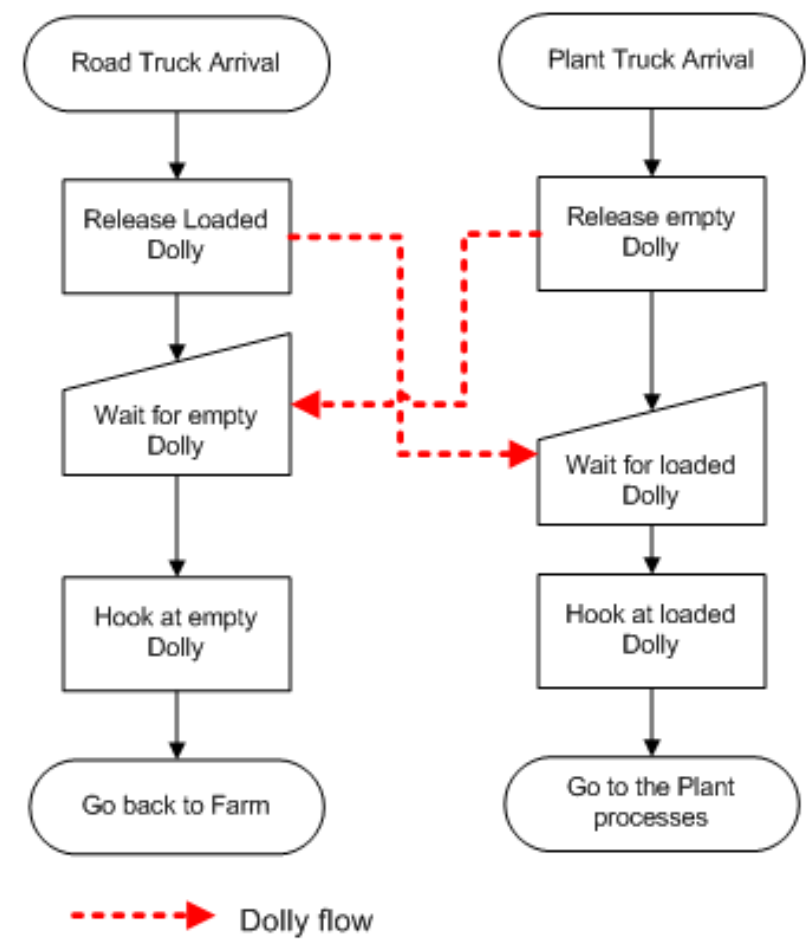

Figure 7: Harvest-transport coupling algorithm. 
The coupling between transport and reception in the plant is done in the called "beat and back yard", so named because road trucks perform quickly the process there. Basically they just arrive, detach the loaded dolly and attach another empty one.

This operation may take longer if there are no empty dollies ready to be taken. These are provided by another part of the process, the internal trucks of the plant. Trucks bring empty dollies for the yard, and perform the reverse process of road trucks. They detach an empty dolly and attach a loaded one, taking it to the unloading process.

Figure 7 illustrates the algorithm of this coupling, that is entirely discrete, but with specific interactions between its components.

\subsection{Processes from Reception to the Mill}

The milling subsystem receives both trucks with chopped and whole cane, and they follow the same process. The unloading consists of depositing the cane on a mill-hopper. The mill-hopper is connected to a conveyor belt system which transports the cane to the mill inlet. Each conveyor goes to a specific mill.

So, the truck unloading is a discrete process. It just drops the cane in the mill-hopper, if there is enough space to receive all their cargo. The process of withdrawal of material of the mill-hopper, performed by the belts, is continuous. This way, the mill-hopper is the connection between the discrete system of trucks and the continuous system of conveyor/mill, as shown in Figure 8.

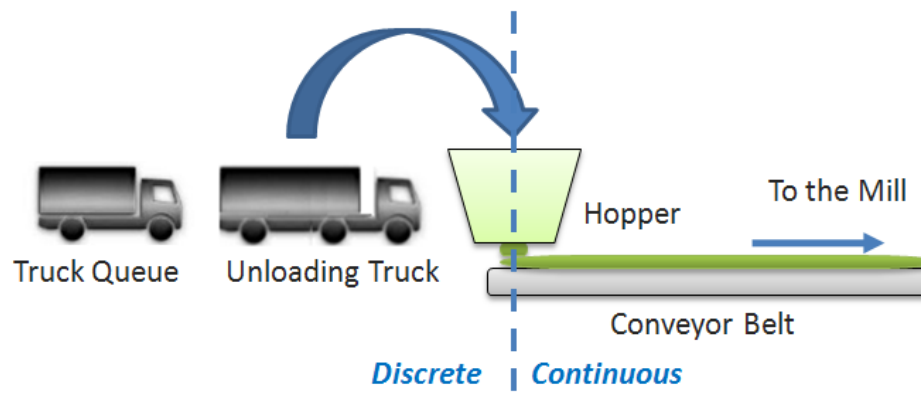

Figure 8: Unloading process.

In the unloading operation, there is a coupling between a discrete and a continuous system. Loaded trucks arrives bringing discrete portions of sugar cane, which must be conducted to the mill by conveyor belts, working continuously.

This representation is more complex than the previous ones, since it involves several factors. One of them is the instantaneous mill capacity.

The unloading points have two functions, the first is to store the value for the volume of material transported by truck in a stock control variable, and the second one is to create entities representing sugar cane to be inserted into the system.

Because in the real system the sugar cane transport to mill is a continuous process, the discretization technique presented by Fioroni et al. (2007) was applied, but with a modification: Here the volume of material to be transported is not a constant, because the milling changes the material consumption rates over time. This causes also a variation to the time intervals between output of material from the unload stock to the belt. This technique has proven to be adequate to model continuous systems with discrete tools, as seen in Coelho et al. (2005) on a strategic study, and Coelho et al. (2009) on a more detailed, operational level, study.

So if the grinding rate is higher, means that the milling is poised to consume a larger amount of material, and the mill-hopper must transfer cane to the belt with a smaller time range, enough to match the mill consumption.

To model this situation it is necessary to know the following information: 
- Milling rate that represents the ability of material consumption for a milling during a given time interval $(\mathrm{t})$, (called Tm(t));

- Conveyor velocity (space / time) (called Vc);

- Distance to be covered by the material on the conveyor, or conveyor size (space) (called Dc);

- Transportation capacity by material (weight/time) (called th);

In possession of such information is possible to calculate the density of the material (called d), which represents the weight of material per unit of conveyor space: $d=t h / V c$

To represent that system, the following information about the system is necessary for the model logic:

- Number of material portions (called NE);

- Travel time of each portion from beginning to ending on the conveyor (called TD);

- Time between portion departures (called TE);

- Weight of each portion (called PE).

This information can all be calculated with the system data presented sooner, using the formulas below:

$$
T D=D c / V c, \quad T E=\frac{T m(t)}{d \times V c \times N E}, \quad \text { and } \quad P E=\operatorname{Tm}(t) / N E .
$$

The change in the value of TE ensures that quantities of material will be forwarded to the Milling according to its current rate of grinding $\operatorname{Tm}(t)$. Figure 9 shows the algorithm followed by this coupling.
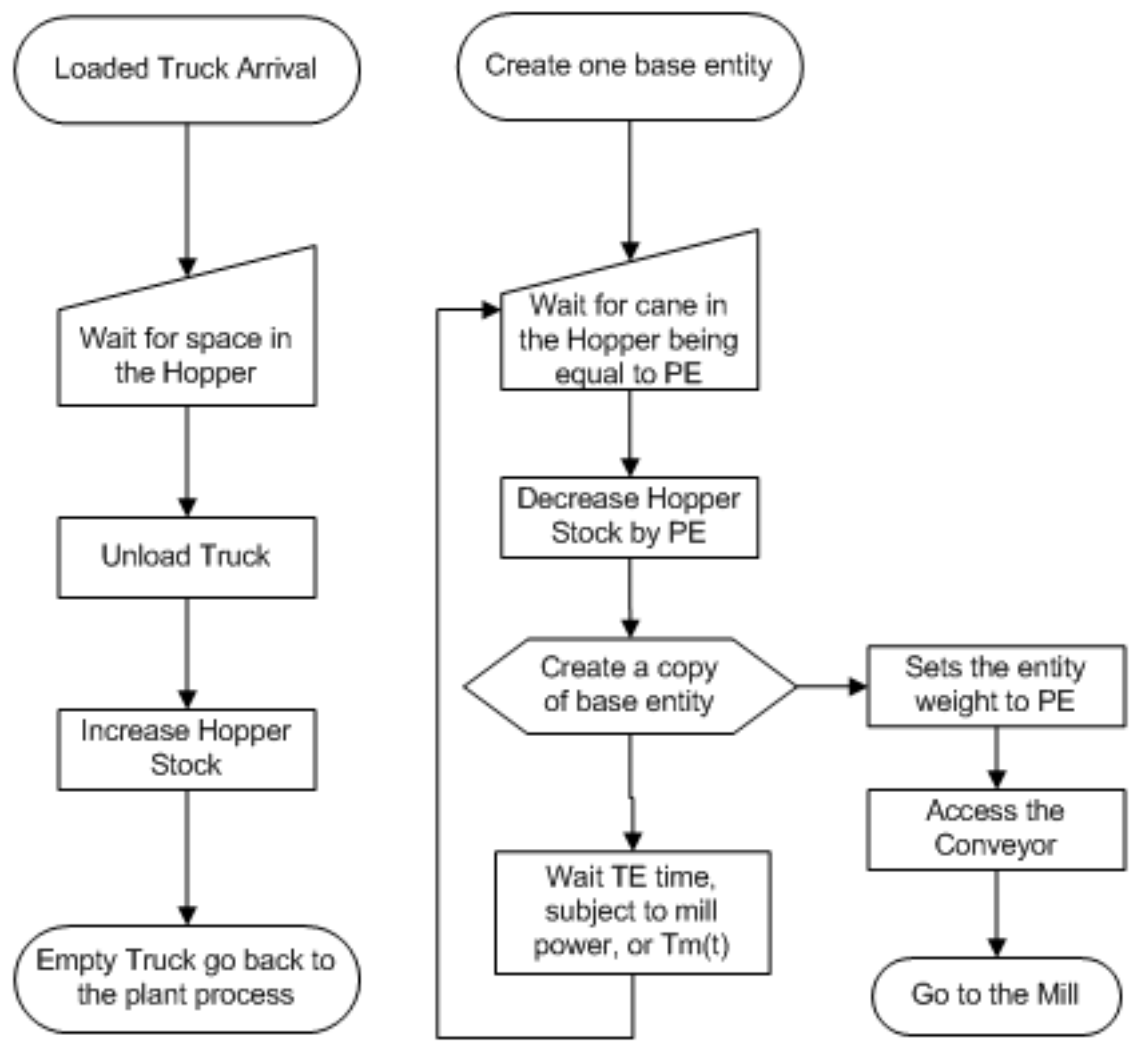

Figure 9: Reception-mill coupling algorithm. 


\section{CASE STUDY}

The presented concepts were applied in the simulation of one ethanol production plant that belongs to Raízen. Raízen is the world's largest sugarcane processor, with 62 million tons of crushing capacity and one of the largest producers and exporters of sugar and ethanol, with 23 production units, in addition to four sugar refineries, two port terminals and business in trading of Agricultural Properties, food brands and production Electric Energy co-generation from the sugarcane straw.

In 2008, Raízen acquired ExxonMobil's and Cosan's downstream assets in Brazil, now called Raízen S/A, raking the 4th largest fuel distributor in Brazil and becoming the first fully integrated renewable energy player in the world. In 2011 Raízen raised the capacity of sugarcane processing to 100 million ton, leading to a production of 6 million ton of sugar, 5 billion liters of ethanol and 1.300 MW of electric energy.

The project was conducted following the methodology described by Filho (2001), which is also based on similar methodologies found on the simulation literature.

Some relevant issues on the system:

- The harvesting points vary over time, because when an area is exhausted, the whole machinery is moved to another location where the cane is ready to be harvested.

- The harvest suffers the impact of rainfall, mainly due to degradation of secondary roads.

- Manual and mechanized harvesting has different characteristics, and is served by different types of trucks.

- The truck fleet is quite varied, both in capacity and type. There is an internal fleet, and another outsourced. Most trucks have coupling with a dolly (cart), allowing interchange loaded and empty dollies.

- The reception has many bureaucratic procedures and quality control. Not all trucks pass through all processes.

- The cane is transported to the mills through a belt conveyor network.

- The mills processing capacity varies over time depending on factors as the availability and quality of sugarcane being consumed. Therefore, its performance can interfere with the discharge and, consequently, in the transport.

The goal of the study was to adjust the truck fleet currently used on the transport of sugar cane in a productive plant, and also to re-evaluate the investment planned for the following year, on the purchase of new trucks. This case highlights the analytical approach taken to preserve CAPEX requirements for fleet vehicles.

\subsection{The Model}

Raízen choose the SIMIO ${ }^{\circledR}$ commercial simulation tool. A new and state of the art 3D rapid modeling simulation software. This is a relatively new tool, but with a great background, since it is being developed by the same creators of SLAM, SIMAN and Arena, well known in this market. The modeling interface mixes the system "drawing" approach where the user can visually put together its system's components, with a flowchart programming approach, allowing the user to describe the behavior of each structure. A better description of SIMIO is made by Pegden and Sturrock (2011).

The process has eight mechanized harvesting fronts (chopped cane) and four fronts of harvest manuals that feed the system and ten different types of trucks to perform the transport. The model works with 32 input variables, 39 output variables, 92 auxiliary variables, 19 input tables, and simulated 240 days (1st season). 


\section{Fioroni, Silva, Franzese, Cerqueira Junior, and Almeida}

The described algorithms were implemented in the model. This process was facilitated by the SIMIO environment, were the more complex logic can be built as a kind of flowchart. The Figure 10 presents an overview of the animation, and Figure 11 shows part of the unload process logic.

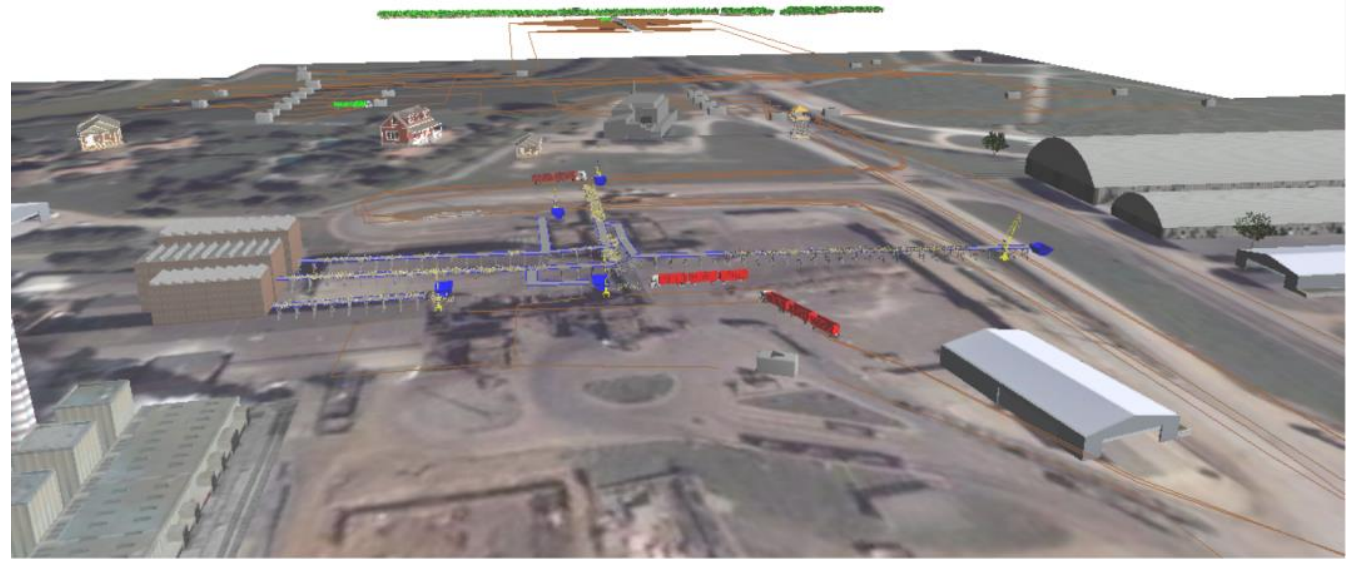

Figure 10: Model animation 3D view.

Basically, the model has a continuous portion, representing the plant processes, and a discrete portion that is the cane transportation by trucks. The plant has hoppers (silos) to receive the cane from trucks, and a conveyor belt network that moves the cane from the hoppers to the mills. These are typically continuous processes. The trucks are discrete elements carrying an amount of cane, and its interface to the continuous system (the conveyor network) is the hoppers, as shown in Figure 8. The algorithm described on Figure 9 was used to develop this interface. Different types of trucks were used, each one with distinct capacities and travel time.

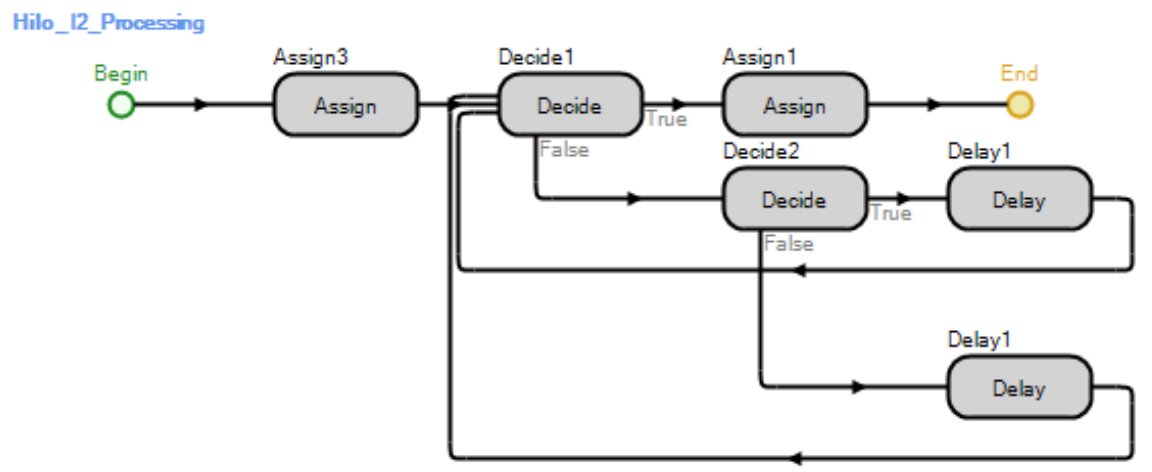

Figure 11: Part of the unloading process logic.

After a determined amount of cane was already loaded into trucks at the farm, the truck travel time increases a little bit. This was used to represent the harvesting evolution, which changes its position. It was assumed that it always evolves away from the plant, increasing the distance to be traveled by the trucks. 


\subsection{Results}

Since the system was not operating at the time of model development, the validation was made based on the algorithms check by system specialists, and by sensibility analysis of the main variables of the system. The model proved to be very similar to the real dynamics of Raízen's operation either for the sugar cane harvest, and internal operations in the plant, confirming that the conceptual model was valid and could be applied to make experiments and support decisions. The search for the best fleet was held according to the following criteria:

\section{Objective:}

- Identify the smallest fleet able to meet the restrictions

\section{Restrictions:}

- Should meet the demand of all harvesting farms.

- The plant mills should never stop due to cane stock out

Various fleet combinations were tried. The best results is shown at Table 1, compared with the CAPEX estimation.

Table 1: Truck fleet results.

\begin{tabular}{|r|r|r|}
\hline & \multicolumn{2}{|c|}{ \#Trucks } \\
\hline Truck Type & CAPEX & Simulation \\
\hline Rodotrem Shattered & 24 & 23 \\
\hline Treminhao Shattered & 9 & 8 \\
\hline Treminhao Whole & 11 & 11 \\
\hline Rodotrem Outsource & 9 & 8 \\
\hline
\end{tabular}

Based on the experiments, the planned 2011 CAPEX fleets (deterministic) were reduced from 53 trucks to 50. Also, bottlenecks were detected and led to a change on the reception queues.

The value gained by using simulation is that plant administration gets a predictive risk analysis. The risk analysis covers a 240-day season at the plant in labor variations, unplanned downtime, non-optimal equipment speeds and other uncertainty.

\section{CONCLUSIONS}

The opportunity to simulate a sugar cane logistic system led to the development of techniques and algorithms to approach the problem. A case study proved the practical implementation of the algorithms presented. The study results were immediately implemented in the process, which is currently operating with the suggested configuration.

The main objective on developing the algorithms was to use them in other models of sugar cane supply-chain system. For sure, this can be done in almost all Raízen plants because they have similar structures. It is also true for other plants. The ones described by Rangel et al. (2010) and Iannoni and Morabito (2002) presents the same structures already, and could be also apply the described algorithms and concepts.

Next steps in the overall effort to improve agricultural operations in Raízen's agricultural logistics operations include detailing the frontend process of mechanized harvesting and expansion of the model to other plants of the group. The Raízen team also plans to use the Simio modeling tool for other agricultural 
operations such as scaling of the truck fleet dollies, which can also be done using the same algorithms on a new model.

\section{ACKNOWLEDGMENTS}

The Authors thanks Raízen by supporting this project and for authorizing the use of its information.

\section{REFERENCES}

Brito, T. B., E. F. C. Trevisan, and R. C. Botter. 2011. "A Conceptual Comparison Between Discrete and Continuous Simulation to Motivate the Hybrid Simulation Technology." In Proceedings of the 2011 Winter Simulation Conference, edited by S. Jain, R.R. Creasey, J. Himmelspach, K.P. White, and M. $\mathrm{Fu}, 3915-3927$. Piscataway, New Jersey: Institute of Electrical and Electronics Engineers, Inc.

Coelho, R.J., and M. M. Fioroni. 2005. Estudo de expansão do sistema de manuseio de matérias-primas da CST através de simulação. In: $60^{\circ}$ Annual ABM Congress. Belo Horizonte, MG, Brazil.

Coelho, R. J., P. F. Lana, A. C. Silva, T. F. Santos, M. M. Fioroni, L. A. G. Franzese, D. O. Mota, and L. B. Silva. 2009. "Operational Simulation Model of the Raw Material Handling in an Integrated Steelmaking Plant." In Proceedings of the 2009 Winter Simulation Conference, edited by M. D. Rossetti, R. R. Hill, B. Johansson, A. Dunkin and R. G. Ingalls 3055-3065. Piscataway, New Jersey: Institute of Electrical and Electronics Engineers, Inc.

Fioroni, M. M., L. A. G. Franzese, J. Furia, L. T. Perfetti, D. Leonardo, N. L. Silva, and C. E. Zanin. 2007. "Simulation of Continuous Behavior Using Discrete Tools: Ore Conveyor Transport." In Proceedings of the 2007 Winter Simulation Conference, edited by S. G. Henderson, B. Biller, M.-H Hsieh, J. Shortle, J. D. Tew, and R. R. Barton, 1977-1985. Piscataway, New Jersey: Institute of Electrical and Electronics Engineers, Inc.

Freitas Filho, P. J. 2001. Introdução à Modelagem e Simulação de Sistemas: Com Aplicações em Arena. Florianópolis: Visual Books. V.1.

Iannoni, A.P., and R. Morabito. 2002. Análise do Sistema Logístico de Recepção de Cana-de-Açúcar: Um Estudo de Caso Usando Simulação Discreta. In Revista Gestão \& Produção, v.9, n.2, p.107-128, august 2002, Universidade Federal de São Carlos, São Carlos, São Paulo, Brazil.

Kuo, S. S., J. E. Chen, P. L. Selikson, and Y. M. Lee. 2001. "Modeling Continuous Flow with DiscreteEvent Simulation." In Proceedings of the 2001 Winter Simulation Conference, edited by B. A. Peters, J. S. Smith, D. J. Medeiros, and M. W. Rohrer 1099-1103. Piscataway, New Jersey: Institute of Electrical and Electronics Engineers, Inc.

O'Reilly, J., M. Sale, and D. Martin. 1985. "The Use of Continuous/Discrete Event Models in Manufacturing." In Proceedings of the 1985 Winter Simulation Conference, edited by D. Gantz, G. Blais, S. Solomon 308-313. Piscataway, New Jersey: Institute of Electrical and Electronics Engineers, Inc. Piscataway, New Jersey: Institute of Electrical and Electronics Engineers, Inc.

Pegden, D., and D. Sturrock. 2011. "Introduction to SIMIO." In Proceedings of the 2011 Winter Simulation Conference, edited by S. Jain, R.R. Creasey, J. Himmelspach, K.P. White, and M. Fu 29-38. Piscataway, New Jersey: Institute of Electrical and Electronics Engineers, Inc.

Rangel, J. J. A., A. P. Cunha, and L. R. Azevedo. 2010. "A Simulation Model to Evaluate Sugarcane Supply Systems." In Proceedings of the 2010 Winter Simulation Conference, edited by B. Johansson, S. Jain, J. Montoya-Torres, J. Hugan, and E. Yücesan, 2114-2125. Piscataway, New Jersey: Institute of Electrical and Electronics Engineers, Inc.

Roth, P. F., 1988. "Discrete, Continuous and Combined Simulation." In Proceedings of the 1988 Winter Simulation Conference, edited by M. Abrams, P. Haigh, and J. Comfort 56-60. Piscataway, New Jersey: Institute of Electrical and Electronics Engineers, Inc.

Stchedroff, N., and R. C. H. Cheng, 2003. "Modeling a Continuous Process with Discrete Simulation Technics and its Applications to LNG Supply Chains." In Proceedings of the 2003 Winter Simulation 
Conference, edited by S. Chick, P. J. Sánchez, D. Ferrin, and D. J. Morrice. 1608-1611. Piscataway, New Jersey: Institute of Electrical and Electronics Engineers, Inc.

Szymanski, B. K., and G. Chen. 2000. "Linking Spatially Explicit Parallel Continuous and Discrete Models." In Proceedings of the 2000 Winter Simulation Conference, edited by J. A. Joines, R. R. Barton, K. Kang, and P. A. Fishwick. 1705-1712. Piscataway, New Jersey: Institute of Electrical and Electronics Engineers, Inc.

\section{AUTHOR BIOGRAPHIES}

MARCELO MORETTI FIORONI is a simulation consultant with an Electrical Engineering degree, MSc. in Manufacturing and PhD in Logistics at University of São Paulo (USP). Has participated in almost 170 successful projects with simulation. Co-founder of PARAGON Tecnologia in 1992, the pioneer and leading consulting company in simulation in South America. Teaches Simulation at Faculdades Metropolitanas Unidas (FMU) in São Paulo, Brazil. Has trained more than 1,200 professionals in simulation. He can be contacted by email at marcelo@paragon.com.br.

DOUGLAS JOSÉ DA SILVA is a simulation consultant with an Industrial Engineering degree. Has participated in almost 20 successful projects with simulation and teaches simulation in Paragon. He can be contacted by email at douglas@paragon.com.br.

LUIZ AUGUSTO G. FRANZESE is a simulation consultant with a Production Engineering degree and MSc. in Logistics, who has completed almost 170 successful projects with simulation. Founded PARAGON Tecnologia in 1992, the pioneer and leading consulting company in simulation in South America. Has trained more than 1,200 professionals in simulation. He can be contacted by email at augusto@paragon.com.br.

MÁRIO JOSÉ BARBOSA CERQUEIRA JÚNIOR is Mechanical Engineer at the Federal University of Espirito Santo (UFES), Master in Industrial Engineering from the Pontifical Catholic University of Rio de Janeiro (PUC-Rio) and an MBA in Finance from the Methodist University of Piracicaba (UNIMEP), worked for over 10 years in Aracruz Celulose S / A as Logistics Manager of Forestry and was a professor of logistics at undergraduate and postgraduate. Currently serving as Manager of Corporate Logistics in Raízen. He can be contacted by email at mario.cerqueira@raizen.com.br.

DANIEL AMORIM DE ALMEIDA is a Naval Engineer graduated at University of São Paulo and Master degree in Naval Engineering with focus on maritime logistics processes. He worked in system consultancy for port and transportation segments and also for fuel and maintenance control of fleets, worked as Logistics Forestry Specialist in Aracruz Celulose S/A and currently is a Logistics Development Manager at Raízen. He can be contacted by email at daniel.almeida@raizen.com.br. 